\title{
Editorial
}

\section{Cell death in the third millennium}

\author{
RA Lockshin ${ }^{\star, 1}$, B Osborne ${ }^{2}$ and Z Zakeri ${ }^{3}$ \\ ${ }^{1}$ Department of Biological Science, St. John's University, Jamaica, New York, \\ NY 11439, USA \\ 2 Veterinary/Animal Science, University of Massachusetts, Amherst, \\ Massachusetts, MA 10013, USA \\ ${ }^{3}$ Department of Biology, Queens College of CUNY, Flushing, New York, NY \\ 11367, USA \\ * Corresponding author: RA Lockshin, Department of Biological Science, St \\ John's University, Jamaica, New York, NY 11439, USA
}

Although one can delineate some trends in current thinking, we should reflect on the ability of working scientists to predict the future. It is poor. ${ }^{*}$ Therefore, though trends now seem to be identifiable with relative clarity, we recognize that fields change rapidly, and we acknowledge that the topic discussed here represents a certain level of hubris. Nevertheless, the last 10 years have seen some remarkable changes. From an original description of apoptosis as inherently a phenomenon of morphology, we have moved to a much more comprehensive understanding of the molecular origins of that morphology, including at least partial understanding of the roles of proteases and nucleases in creating the hallmarks of apoptosis. Many of these advances derive from the cloning and identification of Caenorhabditis genes, which opened the entire horizon of proteases, and led directly to identification of the role of mitochondria in apoptosis. ${ }^{1-10}$ Similarly, identification of pro- and anti-apoptosis mechanisms in human cells (fas and p53; bcl2) and in bacteria and viruses (p35, crmA) has allowed us to glimpse intracellular signaling. For a few specific situations, we can now trace a complete sequence controlling the survival of a cell. ${ }^{11-23}$ Nevertheless, the clarity of these sequences is a bit meretricious. The inherent elegance and simplicity of these concepts (albeit not of the sequences - the simplicity is in the linearity of the scheme) belie at least two orders of complication. The first of these is that, in real life as opposed to a very controlled laboratory

\footnotetext{
${ }^{*}$ Our sense of the reliability of predictions derives from an experience one of us (RA Lockshin) had as an undergraduate and graduate at a well known institution. He twice got very high grades from prominent scientists for totally missing the point. In one, he reviewed the brandnew Medawar and Burnet clonal selection theory, which he dismissed as the old Landsteiner theory with a modern vocabulary. In the other, he had unearthed a relatively obscure reference that contended that, if baby guinea pigs were thymectomized, they would appear to do all right (as did rats) but eventually they became cachectic and died. With appropriate scorn, he noted that better animal husbandry would resolve the problem. He thereby learned that senior scientists are not routinely clairvoyant. In the legalistic sense currently preferred in North America, Europe and elsewhere, the above remarks constitute the legal disclaimer.
}

setting, signaling and transduction are often not linear but are dependent on very specific aspects of cell history and current state. The phase in which researchers expected a linear sequence of events, for instance from signal to transduction to gene activation to caspase activation, is over: The role of a given protein may be entirely contextual. Secondly, as the linear sequences are more precisely defined, it has become apparent that there are many variants to both the broad schemes and the more subtle details. Both of these limitations suggest that it is now time to bring the molecular biology to bear on the somewhat messier situations of apoptosis in vivo and in the situations of sedentary, large, highly differentiated post-mitotic cells, which rarely follow a conventional sequence of apoptosis. We need to accept the idea that the model of apoptosis based on cells of hematopoietic origin is an extremely important paradigm, but it is not universal.

\section{Cells and cell deaths in context}

The role of context may be illustrated by a few examples. Different TNF receptors play different roles in $\mathrm{NF} \kappa \mathrm{B}$ dependent and independent pathways. TNFRI often induces apoptotic signals but in other circumstances is antiapoptotic. ${ }^{24}$ In chick and duck embryos, both condensation of cartilage to form a digit and cell death result from the interactions of BMP, FGFB, and noggin, but the reason for the different responses remains unknown. ${ }^{25}$ Even the paradigmatic inducer of apoptosis, myc, is now consigned to a subtler role: rather than causing apoptosis in some circumstances, myc sensitizes a cell to many inducers of apoptosis; 'myc increases the probability of apoptosis'. ${ }^{26,27}$

\section{Types of cell death: caspases, proteases, and autophagic cell death}

For several years a major discussion point was definition of the type of cell death: apoptosis, programmed, active, physiological, necrotic. Elucidation of some of the molecular pathways has resolved some of these issues, but has indicated that there is sufficient variation that one needs either to take a larger view of the meaning of the word 'apoptosis' or to consider apoptosis to be one of a family of physiological cell deaths. For instance, in the last 10 years caspases have been identified as major players in apoptosis, and have even been proposed as the defining element of apoptosis, ${ }^{28}$ but we also now recognize that the certainly powerful caspase pathway is not necessary to kill cells. Although the discovery of the caspase-mitochondrial pathways unequivocally counts as one of the triumphs of this decade ${ }^{29-37}$ we are now beginning to recognize limits and complications that we need to explore. ${ }^{38-41}$ This is typical of a rapidly-moving and exciting field: the brilliance of the concept draws many researchers who, while not 
undermining the concept, realize that it must be nuanced. For instance, the protease that initiates degradation of chromatin is likely not to be a caspase. ${ }^{42,43}$ In many instances cells in which caspases are blocked or knocked out will die, even though they do not acquire apoptotic morphology. They look more like cells with elaborately developed autophagy, a form of death that is encountered, more commonly than acknowledged, in large postmitotic epithelial and other cells, including insect organs and mammary epithelium. In these cells, lysosomal and perhaps other proteases are activated, though the role of proteasomal proteases remains equivocal. ${ }^{44,45}$ There is growing recognition that autophagic death is not a caspase death and that, in cells destined to die (such as neurons in the absence of NGF) inhibition of caspases may prevent development of apoptotic morphology but neither autophagy nor death of the cell. ${ }^{46}$ There are autophagic pathways even in thymocytes. ${ }^{47}$ In other instances, granzymes play more complex and subtle roles than the original 'bludgeoning' model suggested. ${ }^{48,49}$ We have come full circle, now returning to the investigation of autophagic death that was popular 30-40 years ago. Levi-Montalcini and Aloe noted in 1981 that the types of death of neurons depended on their state of differentiation ${ }^{50}$ and Schweichel and Merker ${ }^{51}$ and Potten ${ }^{52}$ attempted to classify different types of death. These and other variations help to understand why caspase or apaf-1 knockouts, for instance, may yield only modest phenotypes. First, cells may follow parallel or complementary pathways to death, so that knockout of the normal system simply routes the cell through another pathway. Second, embryonic development is highly redundant and embryos are wonderfully adept at compensating for deficits by using secondary controls or even other cells to accomplish the same end.

For autophagic cell death, as with the caspases, the apparent segregation between enzyme and potential substrate remains an issue. Both the fact that these enzymes are typically not made immediately prior to cell death but rather exist in an inactive or compartmentalized state and the fact that they or their substrates appear to be translocated suggest that we need to understand much better the mechanisms of intracellular trafficking and compartmentalization. An entire field remains to be explored. $^{53}$

Also, the physiologies of deaths may differ. We recognize this in acknowledging that the original image of programmed cell death, deriving from developmental biology, was that cell death required protein synthesis. Today, we commonly induce apoptosis by exposing cells to cycloheximide, addressing the contradiction by assuming that the machinery has already been synthesized. In vertebrate (frog and fish) embryos, the ability to undergo apoptosis is acquired during the mid-blastula period. ${ }^{54-56}$

Earlier studies (of programmed cell death) were concerned with the upregulation of genes inducing cell death. Among the genes commonly upregulated in cells dying from deprivation of steroid hormones are those for matrix digesting enzymes, such as stromelysin, collagenase, and cathepsin $B$, suggesting that a very important event in cell death is its severing its connection with its neighbors, or anomie. Several cell biologists have emphasized the importance of cell shape on cell metabolism. ${ }^{57-60}$ These issues are of minimal importance in the case of cells that normally move freely in the body and are studied in suspension culture, but they may be very meaningful for sedentary tissues in vivo and therefore should be considered for all clinical evaluations. Other genes previously attracting interest include genes affecting structure, such as transglutaminase, those now considered to participate in the suppression of inflammation, such as TRPM-2 (SGP2), and genes involved in, or regulating, cell cycle. Their stories are not yet complete, and deserve further attention. Caspases are important enzymes, but, like most biomolecules that are discovered in conjunction with a specific important process, their role is undoubtedly more complex than we picture. For instance, caspases arose in evolution from molecules that presumably had other functions ${ }^{61-65}$ and we have not yet assessed those other functions and determined their importance. Do mammalian cells really carry a complex of more than one dozen proenzymes solely to anticipate their death and graceful exit? In Dictyostelium, caspase inhibitors interfere with development but not apoptosis. Insect cells, which have caspases and display caspase-mediated cell death in vitro, show little sign of activating these enzymes during the paradigmatic programmed cell death of their metamorphosis, ${ }^{66}$ and a functional role for bcl-2 like molecules has not been convincingly demonstrated. In neurons, different caspases function under different conditions: why?

\section{The morphology and molecular biology of cell death}

The mechanics and consequences of the morphological changes of apoptosis, including the phosphatidyl serine flip, depolarizations of mitochondrial and cell membranes, and the modest leakiness that permit use of dye-penetration and -escape assays for apoptosis, are not sufficiently investigated. While two-hybrid screens, flow cytometry, and fluorescence microscopy are marvelous tools, they do not effectively resolve the temporal sequence in individual cells; nor do they achieve the spatial resolution of electron microscopy. It is disappointing that electron microscopic investigation of apoptosis is rather demodé, as there is undoubtedly much that we could learn from electron immunocytochemistry, correlating for instance the movement of caspases, caspase substrates, cytochromes, bcl-2 family members, and other participants in apoptosis. The bcl-2 family is obviously important in cell death, but current controversies regarding the functions and interactions of the several members with themselves, with mitochondria, and with Apaf-1, indicate that we have much to learn. We are always driven by our technology, and our attitudes reflect it. Today our focus is determined primarily by what we can read from the sequence of genes, identify by interactions of two proteins, and observe by fluorescence science (primarily flow cytometry and immunofluorescence) and our sense of what is valid derives primarily by the behavior of cells functioning or reacting in suspension culture. As is noted below (Apoptosis or apoptoses?) we need to seek a 
technology to evaluate the subtle and chronic in vivo behavior.

The importance of the multiple connections of signaling is most readily connoted by the observation of Hager and Hanahan. ${ }^{67}$ They adapted DNA chips to a study of the progress of islet $\beta$ cells to malignancy, using apoptosissensitive and -resistant lines, and found that no known apoptotic genes or modulators are differentially expressed, and that the genes that are differentially expressed are not obviously apoptosis genes. They conclude that there are multiple mechanisms to develop resistance to apoptosis. This may be shocking but it is not surprising: cells that become resistant to apoptosis typically do not lose the apoptosis machinery; they activate it at a substantially higher threshold. Although in some instances this resistance can be traced to adjustment of a specific molecule such as bcl-2, in many other instances it appears to be metabolic. Fas expression is a function of a metabolic shift to glycolysis; ${ }^{68} \mathrm{Bcl}-2$ can sequester a transcriptional repressor such as BTF in the cytoplasm ${ }^{69}$ and control the release of palmitate. ${ }^{70}$ The status of the mitotic apparatus can directly influence the state of phosphorylation of Bcl-2 and hence its function. ${ }^{71}$ More recently, the continuing confusion about the role of ceramide has led researchers to postulate that transient but not chronic rise of ceramide triggers a cascade of events. ${ }^{72}$ Failure of researchers to duplicate this transience has led to the confusion. As in similar instances in similar regions of cell biology, the sensing and transduction of a transient signal, as opposed to theory of a chronic elevation that could be monitored by receptors, is not yet tested.

\section{Cell death and disease}

While the relationship of apoptosis to disease has been postulated and argued in many settings, on one topic there is a building consensus. In diseases as diverse as AIDS, myocardial infarction, hyperoxia in the lung epithelium, immunological irregularities, and autoimmune disease, there is substantial apoptosis, often including cells that appear not to be seriously damaged but may be bystanders activating their cell death pathways in response to local events. ${ }^{73-76}$ In some situations such as $\mathrm{MI}$, massive apoptosis may result in incomplete clearance of apoptotic cells and consequent inflammation. There is growing evidence that the primary antigens of autoimmune disease result from immunization against apoptotic blebs. In all pathological situations, we often know the outline of the origin of the pathology, but we need to understand it with far greater subtlety: the means by which a cell is forced into apoptosis, following what appears to be longterm, chronic stress; by misreading or misdelivery of transcellular signals by other cells (death of bystander cells); by a self-destructive turn of recruitment of phagocytic attack when a chronic infection allows T-cells to be recruited to destroy apoptotic blebs (in autoimmune disease); or the subtle changes in development or cancer in which, without abrogating the apoptotic response, patterns in which cell death occurs are shifted or the sensitivity of cells to normal controls is altered.

At the end of the twentieth century it is clear that the understanding of apoptosis will have an important impact in medicine but where and when it will move above the clinical horizon is not yet defined. Even though fundamental issues of apoptosis were defined by oncological processes-the discovery of bcl-2 from B-Cell Lymphoma, and the realization that mutation of p53 affects apoptosis as well as cell cycle, come to mind-most oncologists are not yet obviously considering the role of apoptosis in tumors, and focus remains essentially entirely on perfecting antimetabolites and antimitotics. Gynecologists, obstetricians, and developmental neurologists are more concerned, as are gerontologists concerned with deterioration in the CNS and in immune function. In contrast, several biotechnology companies are eagerly exploring clinical relevance, and some clinical laboratories are, curiously and perhaps embarrassingly, beginning to report 'apoptosis' figures in clinical laboratory reports ('reference range: $0-5 \%$ '). In 1999, the clinical world is variably interested in the subject, but overall does not know what to make of it. One problem is our habit of thinking generically about 'apoptosis' in the sense that a lay audience might ask for an interpretation of 'cancer' or 'infection'. Before the measurement and regulation of apoptosis can become a clinically important approach, we will need to face several issues:

(a) As we measure apoptosis today, we detect only the final phases, perhaps the last $10 \%$ of dying, and are missing a potentially extensive prologue. It is as if we practiced medicine by taking an interest in patients only when they were moribund. Medical application to prevent apoptosis will require greater knowledge about how the cells reached that state.

(b) Our understanding today is that cells may become resistant to apoptosis (such as those of B-cell lymphomas or those $50 \%$ of tumors that mutate p53) but that they do not lose the capacity to undergo apoptosis: they reset the threshold. Thus the intermediary metabolism and cell biology of the affected cell are very important and may play substantial roles in clinical applications, as is noted in the next point.

(c) The term 'apoptosis' is used as a shibboleth to cover many issues, but we will need not to control 'apoptosis' but to regulate the fate of very specific cells. The targeting of control agents to specific cells or tissues is likely to be the most important clinical consideration, as it is for all oncolytic procedures.

(d) The image of 'apoptosis' as unitary and all-inclusive can easily be misleading. For instance, transient inhibition of one or more caspases at a critical point may protect cells and prevent their loss. Such therapy may be very promising in acute situations such as heart attack and stroke. However, we also know that inhibition of caspases may prevent cells from assuming the morphology or DNA degradation of apoptosis without actually salvaging them. Without their appropriate support mechanisms such as growth factors, cytokines, nutrients, or oxygen, they remain functionless. We also know that not all deaths are caspase-dependent or fas-dependent, and that not all follow the paradigmatic morphological sequence of the 
lymphocyte or thymocyte. To reiterate: several recent papers argue that, following blockage of apoptosis as detected by morphology, failure to activate caspases, or failure to generate DNA ladders, the cells simply die by another option such as autophagic or vacuolar cell death: Blockage of apoptosis is not synonymous with salvage of the cell or maintenance of cell function.

\section{Apoptosis or apoptoses?}

The problem of defining apoptosis is even more complex. To be provocative if jocular, one could argue that apoptosis is a laboratory artifact. Our understanding of how apoptosis is triggered derives heavily from cells that are easy to maintain and handle in suspension culture, and we often induce apoptosis only after we put them in manifestly pecuniary conditions, such as $1 \%$ serum. In a better environment, such as $10 \%$ serum, our efforts to induce apoptosis rarely succeed. We avoid cells that are difficult to maintain, but it is precisely those that we need to know better. With the exception of primary suspensions of thymocytes, most experiments are conducted on transformed cells. The bulk of research is conducted on cells with little cytoplasm and which typically depend more on soluble factors like cytokines and growth factors, rather than on matrix. However, if we look in vivo, most cells die in a context of matrix and other cells; are usually post-mitotic; have substantial cytoplasm; and manifest considerable autophagy prior to death. Most lymphoid cells are not 'in suspension' in vivo. In fact, lymphocytes are most commonly found in tissues like lymph nodes and spleen and touch each other and other cells in the tissue. Experiments using thymocyte or lymphocyte suspensions should routinely be subjected to 'reality checks' of comparison, for instance, to whole thymus. The context argument can at times be striking. In interdigital regions, the cells that die are typically splayed apart by an expanding extracellular matrix, or at least are not coalesced as in the differentiating cartilage. To what extent does their morphology, their decreased ability to maintain cellto-cell contact, or their deprivation from sources of growth factors, influence their fates?

\section{From the twentieth century to the twenty- first century: Cell biology to molecular biology becomes molecular biology to cell biology}

The latter half of the twentieth century has witnessed the rise of genetics and molecular biology, in which the original descriptive observations of programmed cell death and apoptosis have engendered a remarkable genetic analysis of the pathways available to physiological cell death. The key word is 'available'. Today we recognize several pathways, understanding that, depending on context, cells may follow one or another of these pathways. The current proliferation of new death receptors and new family members of cell-deathrelated genes suggests that, rather than linear patterns, we might expect rather fuzzy lines or multi-strand ropes, with many members and participants. More often than not, the response even within a constrained pathway is highly dependent on context. This should not be surprising: in a whole animal context, we concede that the phenotype for an obesity gene is not manifest under conditions of starvation. At the dawn of a new century, it is time to turn the tools of molecular biology to the examination of the most meaningful question of cell biology, regulation. The questions that we ask today concern the context, history, and environment of a cell and how they modulate the inherent and strong pathways that exist in the macro- and microenvironment of the cell and within the cell. The neuron that dies, for instance, in Alzheimer's disease, has undoubtedly fought a long battle and has been heavily supported within its milieu, including the matrix in which it rests and contact with or molecules secreted by its neighboring neurons and glia. Programmed cell death in metamorphosis teaches us that the identifiable apoptotic phase may constitute only the final $10 \%$ of the progress to death, and that there is evidence that what is called apoptosis may be all postmortem. Developmental biology, in helping us to understand how cells contrive to control their lives, may again provide clarity to help us through the more complex aspects of pathology. We can consider this to be the challenge of the third millennium: While we can congratulate ourselves and marvel at how much we have learned, we have another $90 \%$ to study. The notion that death pathways are two-dimensional linear pathways is simplistic and outdated. Cell death is a highly complex multitude of effects and the challenge of the future is to design strategies to understand the context of dying cells.

\section{A final note: Cell Death and Differentiation and its influence}

We think it not a matter of preference or prejudice to state that the journal Cell Death and Differentiation has begun to achieve a level of distinction in its field. The number of papers published each year-9000-10 000-might suggest that impact is randomly distributed. However, of the 10000 papers, perhaps only 2000 receive more than two citations per year, and of those, approximately 100 are in broaderscope journals such as Nature, Cell, and Science. CDD represents a major share of the most important and leading areas. Lead articles have anticipated or helped define major trends: Mitochondria, 8/97 and 6/98; apoptosis in plants, 12/ 97; p75 ${ }^{\mathrm{NTR}}, 5 / 98$; phagocytosis, $7 / 98$; cell death in the central nervous system, 10/98; nitric oxide, 10/99 and throughout; autoantigens, 1/99; and proteases, 10/98, 4/99, and 6/99, to highlight a few. On the question of caspases, of June, 1999 and November, 1999 present both a broad overview of the field and an indication of the controversies yet to be resolved. The quality of its submitted papers is likewise noted, as the papers were well cited even prior to their appearance in MedLine.

The journal serves a function not addressed by both broader and narrower journals. Some journals, for instance, will address a specific step in apoptosis in the context of broader issues of cell biology, not dwelling on the broader meaning of that step and its consistency within the overall story of cell death. Other journals may take a more narrow view depending on the interest of the field-for instance, epidermis, retina, intestinal epithelium, thymocytes, or sensory or motor neurons-without aggressively addressing the issue of comparison of cell death mechanisms in 
different tissues. Cell Death and Differentiation specifically addresses these issues. By bringing together scientists of all stripes, the journal serves as both a forum and a guide for the developing theory of cell death, as opposed to more parochial theories based on a single model system. It is now an essential part of the field, acting as an integrating forum, representing the print version of the central meetings such as the Gordon Conference, the Keystone and Cold Spring Harbor Meetings, and meetings of the AACR, International Cell Death Society (ICDS), and European Cell Death Organization (ECDO). In just 5 years, $C D D$ has become a requirement in the field. Our interests and directions have changed radically and at an accelerating pace in the last $30-40$ years, and the last 5 years have seen several new paradigms sweep through. The overview represented by $C D D$ has provided a sense of direction and meaning as ideas change rapidly. Like other journals that originally branched from a more enveloping basic or clinical branch, the journal has become the journal of record in its field.

\section{Acknowledgements}

In preparing this essay, we have profited from discussions with many colleagues, including most particularly Mauro Piacentini, Gerry Melino, Pierre Golstein, Douglas Green, and Hermann Steller. We are grateful for their reflections and comments. The thoughts expressed here have been generated under the auspices of an NIH grant to RA Lockshin (R15GM/ AG57614 and R25 GM56821).

\section{References}

1. Horvi HR, Shaham S and Hengartner MO (1994) The genetics of programmed cell death in the nematode Caenorhabditis elegans. Cold Spring Harbor Symp. Quantitat. Biol. 59: 377-386

2. Liu QA and Hengartner MO (1999) The molecular mechanism of programmed cell death in C. elegans. In: Zakeri Z, Lockshin RA, Benitez-Bribiesca L. Mechanisms of Cell Death New York City: New York Academy of Sciences 887 92-104

3. Nicholson DW, Ali A, Thornberry NA, Vaillancourt JP, Ding CK, Gallant M, Gareau Y, Griffin PR, Labelle M, Lazebnik YA, Munday NA, Raju SM, Smulson ME, Yamin T-T, Yu VL and Miller DK (1995) Identification and inhibition in the ICE/ CED-3 protease necessary for mammalian apoptosis. Nature 376: $37-43$

4. Tewari M, Quan LT, O'Rourke K, Desnoyers S, Zeng Z, Beidler DR, Poirier GG, Salvesen GS and Dixit VM (1995) Yama/CPP32 beta, a mammalian homolog of CED-3, is a CrmA-inhibitable protease that cleaves the death substrate poly(ADP-ribose) polymerase. Cell 81: 801-809

5. Wu D, Wallen HD and Nunez G (1997) Interaction and regulation of subcellular localization of CED-4 by CED-9 [see comments]. Science 275: 1126-1129

6. Xue D, Shaham S and Horvitz HR (1996) The Caenorhabditis elegans cell-death protein CED-3 is a cysteine protease with substrate specificities similar to those of the human CPP32 protease. Genes Dev. 10: 1073-1083

7. Yuan Jand Horvitz HR (1992) The Caenorhabditis elegans cell death gene ced-4 encodes a novel protein and is expressed during the period of extensive programmed cell death. Development 116: 309-320

8. Yuan J, Shaham S, Ledoux S, Ellis HM and Horvitz HR (1993) The C. elegans cell death gene ced-3 encodes a protein similar to mammalian interleukin-1 betaconverting enzyme. Cell 75: 641-652

9. Zou H, Henzel WJ, Liu X, Lutschg A and Wang X (1997) Apaf-1, a human protein homologous to $\mathrm{C}$. elegans CED-4, participates in cytochrome c-dependent activation of caspase-3 [see comments]. Cell 90: $405-413$

10. Jacotot $E$, Costantini $P$, Laboureau $E$, Zamzani N, Susin SA and Kroemer $G$ (1999) Mitochondrial membrane permeabilization during the apoptotic process. In: Zakeri Z, Lockshin RA, Benitez-Bribiesca L. Mechanisms of Cell Death New York City: New York Academy of Sciences 887: 18-30
11. Abrams JM (1999) Am emerging blueprint for apoptosis in drosophila. Trends Cell Biol. 9: 435-440

12. Bergmann A, Agapite $\mathrm{J}$ and Steller $\mathrm{H}$ (1998) Mechanisms and control of programmed cell death in invertebrates. Oncogene, 17: 3215-3223

13. Bonini NM, Bui QT, Gray-Board GL and Warrick JM (1997) The Drosophila eyes absent gene directs ectopic eye formation in a pathway conserved between flies and vertebrates. Development 124: 4819-4826

14. Bonini NM, Leiserson WM and Benzer S (1998) Multiple roles of the eyes absent gene in Drosophila. Dev. Biol. 196: 42-57

15. Chen P, Rodriguez A, Erskine R, Thach T and Abrams JM (1998) Dredd, a novel effector of the apoptosis activators reaper, grim, and hid in Drosophila. Dev. Biol. 201: $202-216$

16. Dorstyn L, Read SH, Quinn LM, Richardson H and Kumar S (1999) DECAY, a novel drosophila caspase related to mammalian caspase-3 and caspase-7. J. Biol. Chem. 274: 30778-30783

17. Dorstyn L, ColussiPA, Quinn LM, Richardson Hand Kumar S (1999) DRONC, an ecdysone-inducible Drosophila caspase. Proc. Natl. Acad. Sci. U.S.A., 96: 4307-4312

18. Ellis RE, Yuan J and Horvitz HR (1991) Mechanisms and functions of cell death. Annu. Rev. Cell Biol. 7: 663-698

19. Harvey NL and Kumar S (1998) The role of caspases in apoptosis. Adv. Biochem. Eng. Biotechnol. 62: 107-128

20. Kumar S (1999) Regulation of caspase activation in apoptosis: implications in pathogenesis and treatment of disease. Clin. Exp. Pharmacol. Physiol. 26:295303

21. Rodriguez A, Oliver H, Zou H, Chen P, Wang X and Abrams JM (1999) Dark is a Drosophila homologue of Apaf-1/CED-4 and functions in an evolutionarily conserved death pathway. Nat. Cell Biol. 1: 272-279

22. WarrickJM, Paulson HL, Gray-Board GL, Bui QT, Fischbeck KH, Pittman RN and Bonini NM (1998) Expanded polyglutamine protein forms nuclear inclusions and causes neural degeneration in Drosophila. Cell 93: 939-949

23. White K, Grether ME, Abrams JM, Young L, Farrell Kand Steller H(1994)Genetic control of programmed cell death in Drosophila [see comments]. Science 264: $677-683$

24. Lee SY, Reichlin A, Santana A, Sokol KA, Nussenzweig MC and Choi Y (1997) TRAF2 is essential for JNK but not NF-kappaB activation and regulates lymphocyte proliferation and survival. Immunity 7: 703-713

25. Merino R, Ganan Y, Macias D, Rodriguez-Leon J and Hurle JM (1999) Bone morphogenetic proteins regulate interdigital cell death in the avian embryo. In: ZakeriZ, Lockshin RA, Benitez-Bribiesca L. Mechanisms of Cell Death New York City: New York Academy of Sciences 887: 120-132

26. Evan G and Littlewood T (1998) A matter of life and cell death. Science 281: $1317-1322$

27. Juin P, Hueber AO, Littlewood T and Evan G (1999) c-Myc-induced sensitization to apoptosis is mediated through cytochrome c release. Genes Dev. 13: 1367 1381

28. Samali A, Zhivotovsky B, Jones D, Nagata S and Orrenius S (1999) Apoptosis: Cell death defined by caspase activation. Cell Death Differ. 6: 495-496

29. Cecconi $\mathrm{F}$ (1999) Apaf1 and the apoptotic machinery. Cell Death Differ. 6: 1087 1098

30. Ekert PG, Silke J and Vaux DL (1999) Caspase inhibitors. Cell Death Differ. 6: $1081-1086$

31. Kumar S (1999) Mechanisms mediating caspase activation in cell death. Cell Death Differ. 6: 1060-1066

32. Nicholson DW (1999) Caspase structure, proteolytic substrates, and function during apoptotic cell death. Cell Death Differ. 6: 1028-1042

33. Slee EA, Adrain C and Martin SJ (1999) Serial killers: ordering caspase activation in cell death. Cell Death Differ. 6: 1067-1074

34. Stennicke HR and Salvesen GS (1999) Catalytic properties of the caspases. Cell Death Differ. 6: 1054-1059

35. Thornberry NA (1999) Caspases: A decade of death research. Cell Death Differ. 6: $1023-1027$

36. Zeuner A, Eramo A, Peschle Cand De Maria R(1999) Caspase activation without death. Cell Death Differ. 6: 1075-1080

37. Zheng TS, Hunot S, Kuida K and Flavell RA (1999) Caspase knockouts: matters of life and death. Cell Death Differ. 6: 1043-1053

38. Borner C and Monney L (1999) Apoptosis without caspases: an inefficient molecular guillotine. Cell Death Differ. 6: 497-507 
39. Kitanaka C and Kuchino Y (1999) Caspase-independent programmed cell death with necrotic morphology. Cell Death Differ. 6: 508-515

40. Lorenzo HK, Susin SA, Penninger J and Kroemer G (1999) Apoptosis inducing factor (AIF): a phylogenetically old, caspase-independent effector of cell death. Cell Death Differ. 6: 516-524

41. Vaux DL (1999) Caspases and apoptosis biology and terminology. Cell Death Differ. 6: $493-494$

42. Liu QY, Ribecco M, Pandey S, Walker PR and Sikorska M (1999) Apoptosisrelated functional features of the DNasel-like family of nucleases. In: Zakeri Z, Lockshin RA, Benitez-Bribiesca L. Mechanisms of Cell Death New York City: New York Academy of Sciences 887: 60-76

43. Walker PR, Leblanc J, Carson C and Sikorska M (1999) Neither caspase-3 nor DNA fragmentation factor is required for high molecular weight DNA fragmentation in apoptosis. In: Zakeri Z, Lockshin RA, Benitez-Bribiesca L. Mechanisms of Cell Death New York City: New York Academy of Sciences 887: $48-59$

44. Halaby R, Zakeri Z and Lockshin RA (1994) Metabolic events during programmed cell death in insect labial glands. Biochem. Cell Biol. 72: 597-601

45. Lockshin RA and Zakeri Z (1994) Programmed cell death: Early changes in metamorphosing cells. Biochem. Cell Biol. 72: 589-596

46. Xue L, Fletcher GC and Tolkovsky AM (1999) Autophagy is activated by apoptotic signalling in sympathetic neurons: An alternative mechanism of death execution. Mol. Cell. Neurosci. 14: 180-198

47. Scaffidi C, Schmitz I, Zha J, Korsmeyer SJ, Krammer PH and Peter ME (1999) Differential modulation of apoptosis sensitivity in CD95 type I and type II cells. J. Biol. Chem. 274: 22532-22538

48. Browne KA, Blink E, Sutton VR, Froelich CJ, Jans DA and Trapani JA (1999) Cytosolic delivery of granzyme $B$ by bacterial toxins: evidence that endosomal disrupution, in addition to transmembrane pore formation, is an important function of perforin. Mol. Cell Biol. 19: 8604-8615

49. Heibein JA, Barry M, Motyka B and Bleackley RC (1999) Granzyme B-induced loss of mitochondrial inner membrane potential (DeltaPsim) and cytochrome $\mathrm{C}$ release are caspase independent. J. Immunol. 163: 4683-4693

50. Levi-Montalcini R and Aloe L (1981) Mechanism(s) of action of nerve growth factor in intact and lethally injured sympathetic nerve cells in neonatal rodents. In: Bowen ID, Lockshin RA. Cell Death in Biology and Pathology I London and New York: Chapman and Hall pp 295-327

51. Schweichel JU and Merker HJ (1973) The morphology of various types of cell death in prenatal tissues. Teratology 7: 253-266

52. Potten CS, Merritt A, Hickman J, Hall P and Faranda A (1994) Characterization of radiation-induced apoptosis in the small intestine and its biological implications. Int. J. Radiat. Biol. Relat. Studies Phys. Chem. Med. 65: 71-78

53. Zhivotovsky B, Samali A, Gahm A and Orrenius S (1999) Caspases: their intracellular localization and translocation during apoptosis. Cell Death Differ. 6 : 644-652

54. Hensey C and GautierJ (1997) A developmental timer that regulates apoptosis at the onset of gastrulation. Mech. Dev. 69: 183-195

55. Hensey C and Gautier J (1999) Developmental regulation of induced and programmed cell death in Xenopus embryos. In: ZakeriZ, Lockshin RA, BenitezBribiesca L. Mechanisms of Cell Death New York City: New York Academy of Sciences 887: 105-119

56. Ikegami R, Hunter P and Yager TD (1999) Developmental activation of the capability to undergo checkpoint-induced apoptosis in the early zebrafish embryo. Dev. Biol. 209: 409-443

57. Boudreau N, Sympson CJ, Werb Z and Bissell MJ (1995) Suppression of ICE and apoptosis in mammary epithelial cells by extracellular matrix. Science 267:891893
58. Boudreau N, Werb Z and Bissell MJ (1996) Suppression of apoptosis by basement membrane requires three-dimensional tissue organization and withdrawal from the cell cycle. Proc. Natl. Acad. Sci. U.S.A. 93: 3509-3513

59. Chen CS, Mrksich M, Huang S, Whitesides GM and Ingber DE (1997) Geometric control of cell life and death. Science 276: 1425-1428

60. LundLR, RomerJ, ThomassetN, Solberg H, PykeC, Bissell MJ, DanoKandWerb Z (1996) Two distinct phases of apoptosis in mammary gland involution: Proteinase-independentand-dependentpathways. Development 122: 181-193

61. Ameisen J-C (1999) The evolutionary origin and role of programmed cell death in single-celled organisms: A new view at executioners, mitochondria, hostpathogen interactions, and the role of death in the process of natural selection. In: Lockshin RA, Zakeri Z, Tilly JL. When Cells Die: A Comprehensive Evaluation of Apoptosis and Programmed Cell Death New York: Wiley-Liss pp 3-56

62. Ameisen JC (1996) The origin of programmed cell death. Science 272: 1278 1279

63. Cornillon S, Foa C, Davoust J, Buonavista N, Gross JD and Golsteini P (1994) Programmed cell death in Dictyostelium. J. Cell Sci. 107: 2691-2704

64. Golstein P (1998) Cell death in us and others [editorial]. Science 281: 1283

65. Olie RA, Durrieu F, Cornillon S, Loughran G, Gross J, Earnshaw WC and Golstein P (1998) Apparent caspase independence of programmed cell death in Dictyostelium. Curr. Biol 8: 955-958

66. Facey C, Chaudhry A, Balgobia B and Lockshin RA (1999) Caspases, cathepsins, and other proteases in programmed cell death in metamorphosis. Absts. ESH-ECDO Seventh Eur. Conf. Apoptosis. p.51

67. Hager JH and Hanahan D (1999) Tumor cells utilize multiple pathways to downmodulate apoptosis: Lessons from a mouse model of islet cell carcinogenesis. In: ZakeriZ, Lockshin RA, Benitez-Bribiesca L. Mechanisms of Cell Death New York City: New York Academy of Sciences 887: 150-163

68. Newell MK, Harper M-E, Fortner K, Desbarats J, Russo A and Huber SA (1999) Does the oxidative/glycolytic ratio determine proliferation or death in immune recognition? In: ZakeriZ, Lockshin RA, Benitez-Bribiesca L. Mechanisms of Cell Death New York: New York Academy of Sciences 887: 77-82

69. Kasof GM, Goyal L and White E (1999) Btf, a novel death-promoting transcriptional repressor that interacts with Bcl-2-related proteins. Mol. Cell Biol. 19: 4390-4404

70. Zhang J, Driscoll TA, Hannun YA and Obeid LM (1998) Regulation of membrane release in apoptosis. Biochem. J. 334: 479-485

71. Haldar S, Jena Nand Croce CM (1994) Antiapoptosis potential of bcl-2 oncogene by dephosphorylation. Biochem. Cell Biol. 72: 455-462

72. Kolesnick R and Hannun YA (1999) Ceramide and apoptosis [letter]. Trends Biochem. Sci. 24: 224-225

73. Finkel TH, Tudor-Williams G, Banda NK, Cotton MF, Curiel T, Monks C, Baba TW, Ruprecht RM and Kupfer A (1995) Apoptosis occurs predominantly in bystander cells and not in productively infected cells of HIV- and SIV-infected lymph nodes. Nature Med. 1: 129-134

74. Finkel TH and CasellaCR(1998) AIDS and Cell Death. In:Lockshin RA, ZakeriZ, Tilly JL. Why cells die: A comprehensive evaluation of apoptosis and programmed cell death New York: Wiley-Liss pp 289-318

75. Gougeon M-L and Montagnier L (1999) Programmed cell death as a mechanism of CD4 and CD8 T cell deletion in AIDS: Molecular control and effect of highly active anti-retroviral therapy. In: Zakeri Z, Lockshin RA, Benitez-Bribiesca L. Mechanisms of Cell Death New York City: New York Academy of Sciences 887: 199-212

76. Garaci E, Caroleo MC, Aloe L, Aquaro S, Piacentini M, Costa N, Amendola A, Micera A, Calio R, Perno CF and Levi-Montalcini R (1999) Nerve growth factor is an autocrine factor essential for the survival of macrophages infected with HIV. Proc. Natl. Acad. Sci. U.S.A. 96: 14013-14018 